\title{
A CONSTITUIÇÃO CIDADÃ, A PROTEÇÃO DA FAMÍLIA E A (DES)CONSTRUÇÃO DO DIREITO DAS FAMÍLIAS
}

\section{THE CITIZEN CONSTITUTION, THE PROTECTION OF THE FAMILY AND THE (DE)CONSTRUCTION OF FAMILY LAW}

\author{
Maria Walkíria de Faro Coelho Guedes Cabral \\ Universidade Federal de Lavras - UFLA - (Lavras, MG, Brasil) \\ Jéssica Rodrigues Godinho \\ Pontifícia Universidade Católica de Minas Gerais - PUC Minas - (Belo Horizonte, MG, Brasil) \\ Recebimento: 30 abr. 2018 \\ Aceitação: 14 jul. 2018
}

\begin{abstract}
Como citar este artigo / How to cite this article (informe a data atual de acesso / inform the current date of access):
CABRAL, Maria Walkíria de Faro Coelho Guedes; GODINHO, Jéssica Rodrigues. A Constituição Cidadã, a proteção da família e a (des)construção do direito das famílias. Revista da Faculdade de Direito UFPR, Curitiba, PR, Brasil, v. 63, n. 3, p. 61-80, set./dez. 2018. ISSN 2236-7284. Disponível em: <https://revistas.ufpr.br/direito/article/view/59212>. Acesso em: 22 dez. 2018. DOI: http://dx.doi.org/10.5380/rfdufpr.v63i3.59212.
\end{abstract}

\section{RESUMO}

Esta pesquisa visa a analisar a metodologia civil-constitucional aplicada ao Direito das Famílias, após a Constituição de 1988, nomeada "Constituição Cidadã", em homenagem ao seu trigésimo aniversário. Pretende-se apresentar a proteção concedida pela Constituição às famílias e, em especial, aos indivíduos formadores da família, propiciando o desenvolvimento pessoal de cada membro. Com isso, verificar-se-á que o afeto é o maior link entre os membros de uma família e que, mediante a interpretação dos princípios e preceitos constitucionais, não há que se falar em uma limitação do rol do que é ou pode ser considerado como família. Por fim, tratar-se-á das novas espécies de família, como forma de exemplificar a desnecessidade e impossibilidade de se estabelecer de forma taxativa a proteção a apenas alguns formatos de família. Para a realização da pesquisa, utilizou-se a vertente metodológica jurídico-sociológica, o raciocínio dedutivo-dialético e o método teórico, para, ao final, consolidar-se a diversidade dos modelos de família e defender-se a proteção constitucional a todos os modelos existentes ou que porventura venham a existir.

PALAVRAS-CHAVE

Constitucionalização. Direito Civil. Direito das Famílias. Proteção. Famílias Plurais.

\begin{abstract}
This research aims to analyze the civil-constitutional methodology applied to Family Law, after the Constitution of 1988, named "Citizen Constitution", in honor of its thirtieth anniversary. The intention is to present the protection granted by the Constitution to the families, and, in particular, to the individuals forming the family, providing the personal development of each member. With this, it will be verified that the affection is the greatest link between the members of a family and that, through the interpretation of constitutional principles and precepts, it is not necessary to speak about a limitation of the role of what is or can be considered as family. Finally, it will be presented the new types of family, as a way of exemplifying the needlessness and impossibility of establishing in a
\end{abstract}


restrictive way the protection of only a few family formats. In order to accomplish the research, a juridical-sociological methodological aspect, a deductive-dialectical reasoning and a theoretical method were used, to consolidate the diversity of family models and defend the constitutional protection of all existing and possible models.

\section{KEYWORDS}

Constitutionalization. Civil Law. Family Law. Protection. Plural Families.

\section{INTRODUÇÃO}

A Constituição da República Federativa do Brasil, que recebeu a alcunha de "Constituição Cidadã”, completa, no ano de 2018, 30 anos de existência, que foram marcados por privilegiar direitos humanos e garantias fundamentais. Tão evidente é esse viés protecionista, que os direitos e garantias foram positivados já nos primeiros artigos da Constituição, ao contrário do que aconteceu com as outras Cartas Magnas brasileiras.

Essa nova metodologia, trazida pela Lei Maior de 1988, influenciou todo o sistema infraconstitucional a adequar suas normas ou a fazer uma nova leitura de seus dispositivos, considerando os princípios erigidos contemporaneamente. É nesse contexto que surge a corrente de constitucionalização do Direito Civil.

Não se pretende a extinção do direito privado, contudo, hodiernamente, a dicotomia Direito Público/Direito Privado subsiste para fins acadêmicos, mas, na prática do Direito, essa separação é constantemente superada pela aplicação de princípios específicos de uma seara a outra e do intercâmbio de raciocínios viabilizado pela interpretação sistemática do Direito.

O Direito das Famílias, um dos pilares do Direito Civil, não é imune (e nem poderia ser) a essa constitucionalização do sistema jurídico. Assim, os institutos específicos a esse campo devem ser interpretados à luz dos princípios constitucionais e de novas realidades sociais, que se baseiam no princípio da dignidade da pessoa humana e, mais especificamente, no direito ao livre desenvolvimento da personalidade.

Desse modo, visa-se investigar acerca da proteção constitucional dispensada ao Direito das Famílias quanto às espécies de família existentes e da contínua (des)construção pela qual esse campo passa. Utilizou-se para a pesquisa a vertente metodológica jurídico-sociológica, o raciocínio dedutivo-dialético e o método teórico.

Inicia-se o presente estudo com o importante critério de constitucionalização do Direito Civil, discorrendo-se sobre essa novel metodologia de aplicação hermenêutica. Após, tratar-se-á da 
proteção conferida pela Constituição de 1988 às famílias, para, ao fim, mencionar-se sobre os novos modelos de família.

\section{CONSTITUCIONALIZAÇÃO DO DIREITO CIVIL}

O Direito das Famílias é considerado, por doutrinadores como Luiz Edson Fachin e Carlos Eduardo Pianovski [201-], o terceiro pilar do Direito Civil, e por isso passa por transformações profundas desde a implementação da metodologia civil-constitucional de aplicação hermenêutica do Direito Privado.

Antes de adentrar no Direito das Famílias propriamente, é importante entender como é trabalhado o Direito Civil Contemporâneo, sob esse "novo" aspecto constitucional que se faz presente desde o advento da Constituição Federal de 1988 (CF/88).

Há muito o que se falar a respeito da Constitucionalização do Direito Civil. No entanto, para direcionar o presente artigo ao Direito das Famílias, a aplicação do Direito Constitucional a este instituto e sobre suas transformações, caberá a compreensão da metodologia civil-constitucional que foi tão bem trabalhada por juristas como Anderson Schreiber e Carlos Konder (2016).

De acordo com Maria Celina Bodin de Moraes (2014, s.p.), a metodologia civilconstitucional ocorreu de acordo com a formulação de Pietro Perlingieri, buscando-se assegurar a democracia, a solidariedade e a dignidade na seara do Direito Privado. Ainda conforme a autora:

Uma das características fundantes do direito civil-constitucional é a aplicação direta dos princípios constitucionais às relações privadas, tais como o livre desenvolvimento da personalidade, a igualdade substancial e o direito à diferença, a tutela da privacidade e da integridade psicofísica e a solidariedade familiar e social, todos reunidos e ponderados no âmbito do princípio maior de proteção à dignidade da pessoa humana. (MORAES, 2014, s.p.).

É fato que o Direito Civil Contemporâneo parte da metodologia civil-constitucional de modo a atender a sociedade, em constante evolução, em relação às suas expectativas, esperanças, desejos e até mesmo projetos de vida diante da realidade que lhe é imposta. Dessa forma, o "novo" Direito Civil deve ser constantemente construído para ser livre, justo e, principalmente, solidário (SHREIBER; KONDER, 2016), sendo esta última característica pouco observada nas versões mais clássicas e engessadas do Direito Civil moderno.

Schreiber e Konder (2016) observam que o Direito Civil Constitucional irá se opor à clássica summa divisio do direito privado em relação ao direito público. Assim, a separação entre Direito Privado e Direito Público não terá mais espaço diante da hermenêutica constitucional aplicada ao 
Direito Civil, principalmente no Direito das Famílias, que irá demandar exercícios de ampliação valorativa pelo Poder Público, ao reconhecer, em várias situações, a afetividade como cerne das formações familiares contemporâneas.

Com tal abordagem, a metodologia civil-constitucional opõe-se à clássica summa divisio do ordenamento, cindido em direito público e direito privado [...]. Com o posicionamento da Constituição no ápice do ordenamento e o reconhecimento de que tanto o chamado direito público como o dito privado devem servir à realização dos preceitos constitucionais, a distinção passa a atender a uma finalidade mais didática do que ontológica, uma vez que ambos compartilham o mesmo fundamento e apontam para a mesma finalidade (SCHREIBER; KONDER, 2016, p. 12).

A nova perspectiva do Direito Civil deverá se opor também à ideia de “microssistemas”, que segregava valores e princípios gerando sistemas normativos opostos que, ao se comunicarem, gerava embates principiológicos desnecessários ${ }^{1}$.

Deve-se mencionar as características tidas como essenciais para essa metodologia do direito civil-constitucional, quais sejam: “[...] a prevalência das situações existenciais sobre as patrimoniais (ou a subordinação destas àquelas); a preocupação com a historicidade e a relatividade na interpretação-aplicação do direito [...].” (MORAES, 2014, s.p.). Por tratar o Direito das Famílias de situações extrapatrimoniais (apesar de haver nas uniões o regime de bens, de caráter patrimonial), fica patente a necessidade de se proteger os componentes da família, que devem ter sua dignidade protegida quando do desenvolvimento de sua personalidade.

Essa constitucionalização promoveu, então, uma “nova” forma de ver o Direito Civil, agora sob a perspectiva da primazia do ser sobre o ter. É o momento de despatrimonialização do Direito Civil, para dar lugar à realização da dignidade da pessoa humana.

Deve-se pensar na aplicação das normas constitucionais para os institutos do Direito Civil, principalmente, para os institutos de direitos das famílias, como forma de integrar o sistema jurídico.

De acordo com Gustavo Tepedino (2009a), o ordenamento jurídico tem em si duas características, que são a unidade e a complexidade. Como ele é constituído de normas de diferentes níveis hierárquicos, é um "sistema heterogêneo e aberto: daí a sua complexidade que, por sua vez, só alcançará a unidade caso seja assegurada a centralidade da Constituição, que contém a tábua de valores que caracterizam a identidade cultural da sociedade.” (TEPEDINO, 2009a, p. 10-11).

\footnotetext{
${ }^{1}$ Para além dos microssistemas, ocorre também uma aproximação dos sistemas jurídicos, minimizando as contrariedades normativo-principiológicas anteriormente existentes. Seria o caso de entender questões de direito das famílias e de direito previdenciário sob princípios independentes, que ao se comunicarem (como, por exemplo, em casos de pensão por morte do companheiro) não mais correrão o risco de entrar em choque, pois há de prevalecer o sistema jurídico constitucionalmente reconhecido como unitário.
} 
Assim, não é porque um sistema possui diversas fontes que perderá a sua unidade. É a função da Constituição harmonizar todas as regras sistematizadas para garantir essa unidade. É exatamente por conta dessa necessidade que, durante a aplicação das normas aos casos concretos, deve-se fazêlo “[...] à luz dos princípios emanados pela Constituição da República, que centraliza hierarquicamente os valores prevalentes no sistema jurídico, devendo suas normas, por isso mesmo, incidir diretamente nas relações privadas.” (TEPEDINO, 2009a, p. 12).

Nesse sentido, o Direito das Famílias será diretamente transformado, deixando de ser visto por uma ótica de institucionalização do afeto (ou mesmo, patrimonialização do afeto) para ser contemplado sob a perspectiva de proteção e promoção da dignidade da pessoa humana.

\subsection{A PREVALÊNCIA DA DIGNIDADE DA PESSOA HUMANA NO DIREITO CIVIL}

A dignidade da pessoa humana é imperativo ético, consagrado pela Constituição de 1988 logo em seu primeiro artigo. É também valor, cuja prevalência é prima facie a determinar toda concretização normativa.

Nesse sentido, a dignidade da pessoa humana é, ainda, tutela geral da personalidade. Corrobora com essa afirmação Elimar Szaniawski, que defende a ideia de um direito geral de personalidade, sob o fundamento de que

A Constituição brasileira, em vigor, edifica o direito geral de personalidade a partir de determinados princípios fundamentais nela inseridos, provenientes de um princípio matriz que consiste no princípio da dignidade da pessoa humana. Os princípios constitucionais, dispostos na Carta Magna, constituem um arcabouço da tutela da pessoa humana em nível constitucional, como um grande sistema de proteção do direito geral de personalidade. Tendo em vista a importância e a extensão do princípio da dignidade da pessoa humana, como princípio matriz, do qual irradiam todos os direitos fundamentais do ser humano, vinculando o poder público como um todo, bem como os particulares, pessoas naturais ou jurídicas e sendo o direito da pós-modernidade um direito que possui por destinatário final a pessoa humana, exercendo uma função social, todo o direito posto deve ser lido e interpretado à luz da Constituição, em especial, segundo os postulados do princípio da dignidade da pessoa humana. (SZANIAWSKI, 2005, p. 120-121, grifos do autor).

Fachin e Pianovski [201-] afirmam que a dignidade da pessoa humana não pode ser tomada como exercício teórico do legislador constituinte e, conforme João Baptista Vilela (2009), muito menos do aplicador de norma. Trata-se de um vetor fundamental de operacionalização dos institutos jurídicos do Direito Público e do Direito Privado.

Nos mostram ainda Fachin e Pianovski [201-] que o diferencial da proposta contemporânea acerca da dignidade da pessoa humana deve ser uma ruptura com a lógica racionalista sob a qual se 
estrutura todo o direito moderno, para abrir espaço a uma ética da alteridade que possa sustentar esse valor da sociedade contemporânea.

Nessa lógica, a dignidade, tal como proposta pelo filósofo moderno Immanuel Kant, já não mais é passível de prosperar, pois a onda liberal promovida pela Modernidade gerou, segundo Fachin e Pianovski [201-], um paradoxo da negação do humano. Nesse sentido, a razão moderna reduziu-se à razão instrumental. A necessidade de previsibilidade e controle colocou a tudo e a todos em um espaço científico que abstrai o objeto e o sujeito como entes entre os quais há inafastável cisão.

Assim, a ideia de um conceito normativo de pessoa não mais pode ser vista com o olhar do direito moderno, sendo necessária a revisitação do instituto pelas perspectivas filosóficas contemporâneas, a fim de dar operabilidade às potencialidades humanas, propiciando o livre desenvolvimento de cada indivíduo.

\subsection{A APROXIMAÇÃO DOS DIREITOS MATERIAIS E PROCESSUAIS COMO RESULTADO DA CONSTITUCIONALIZAÇÃO DO DIREITO CIVIL}

A constitucionalização do Direito Civil aproximou os sistemas processuais e materiais, pela vinculação principiológica fundada na Constituição de 1988. Nesse sentido, o processo de constitucionalização do Direito Civil trouxe significativas mudanças, porém muitas delas de forma lenta e gradual. É o caso das alterações na legislação processual civil, em especial no tocante aos direitos das famílias, isto é, em relação às chamadas ações de família.

A primeira mudança a se observar no diploma processual de 2015 é a criação de um capítulo referente exclusivamente às ações de família. Esse novo capítulo foi enumerado como o décimo capítulo do título III, referente aos procedimentos especiais.

A criação de um capítulo específico para tratar das ações de família demonstra um grande avanço para o Direito das Famílias e consagra o início daquilo que Flávio Tartuce (2016) vai chamar de “cultura da paz” em detrimento da “cultura da guerra”, o que vai demandar uma mudança de hábito dos servidores e demais profissionais envolvidos no Direito das Famílias. Essa mudança atende ao princípio da dignidade da pessoa humana, na medida em que visa garantir os direitos dos sujeitos envolvidos em questões familiares, sem que estes se percam pelo longo caminhar processual para a efetivação de tais direitos.

Em outras palavras, trata-se de uma mudança de percepção quanto ao processo, deixando de lado a crença no litígio como lugar de perdas de um lado e ganhos de outro, dando lugar à ideia da 
autocomposição na qual as partes são senhoras de suas capacidades, podendo conciliar, mediar e solucionar suas questões.

Outra questão civil/processual/constitucional que subsiste com as alterações da lei processual é relativa à manutenção do instituto da separação judicial, deixando claro que esse ainda deverá ser de alguma forma considerado dentro do ordenamento jurídico brasileiro, dando uma roupagem à Emenda Constitucional $n^{0} 66$ do ano de 2010, ao se apegar na possibilidade (“o casamento pode ser dissolvido pelo divórcio”), dando força ao instituto da separação que por muitos civilistas já fora rejeitado. Dessa forma, está latente a relação entre os diplomas materiais, legais e a Constituição, como se dialogassem, ainda que de forma aparentemente divergente.

\section{A PROTEÇÃO DA FAMÍLIA PELA CONSTITUIÇÃO FEDERAL DE 1988}

Em uma conceituação de família, Cristiano Chaves de Farias e Nelson Rosenvald mencionam que ela é "[...] o lugar adequado em que o ser humano nasce inserido e, merecendo uma especial proteção do Estado, desenvolve a sua personalidade em busca da felicidade e da realização pessoal.” (FARIAS, ROSENVALD, 2014, p. 43, grifo dos autores).

Assim, entende-se que com a Constituição Cidadã, que trouxe novos parâmetros de proteção do ser humano e de sua dignidade, o indivíduo passou a ser pensado e protegido em todas as suas potencialidades e nas suas relações sociais. Nesse sentido:

A Constituição da República traduziu a nova tábua de valores da sociedade, estabeleceu os princípios fundantes do ordenamento jurídico e, no que concerne às relações familiares, alterou radicalmente os paradigmas hermenêuticos para a compreensão dos modelos de convivência e para a solução dos conflitos intersubjetivos na esfera da família. (TEPEDINO, 2009b, p. 255).

A família, assim, é uma das instituições formadas pelo indivíduo que merece especial atenção e proteção estatal, pois, é na família que o ser humano tem suas bases, contato com outros indivíduos, aprende valores e desenvolve sua personalidade de maneira significativa.

Essa instituição, por ser um fenômeno social, passou por diversas mudanças, na medida em que as transformações sociais foram e são operadas e, por isso, sua proteção também se modifica. Assim, a família do Código Civil de 1916 e da anterior Constituição Federal de 1967 (modificada pela Emenda Constituição - EC - nº 01/69, que, muitos, a exemplo de José Afonso da Silva, entendem que foi a última Constituição antes da de 1988) era entendida como uma "unidade produtiva e reprodutiva” (FARIAS; ROSENVALD, 2014, p. 86). O ato sexual estava ligado à reprodução e perpetuação da espécie, não se considerando o fator pessoal e de satisfação do ato. Não se considerava 
também a individualidade dos componentes da família, que aquele deveria ser um espaço para o desenvolvimento pessoal de cada membro.

A família, na Constituição de 1967, com redação dada pela EC nº 01/69, tinha sua proteção específica e direcionada em apenas um artigo:

Art. 175. A família é constituída pelo casamento e terá direito à proteção dos Podêres Públicos.

$\S 1^{\circ}$ - O casamento somente poderá ser dissolvido, nos casos expressos em lei, desde que haja prévia separação judicial por mais de três anos. (Redação da pela Emenda Constitucional ${ }^{\circ}$ 9, de 1977)

$\S 2^{\circ} \mathrm{O}$ casamento será civil e gratuita a sua celebração. O casamento religioso equivalerá ao civil se, observados os impedimentos e prescrições da lei, o ato fôr inscrito no registro público, a requerimento do celebrante ou de qualquer interessado.

$\S 3^{\circ} \mathrm{O}$ casamento religioso celebrado sem as formalidades do parágrafo anterior terá efeitos civis, se, a requerimento do casal, fôr inscrito no registro público, mediante prévia habilitação perante a autoridade competente.

$\S 4^{\circ}$ Lei especial disporá sôbre a assistência à maternidade, à infância e à adolescência e sôbre a educação de excepcionais. (BRASIL, 1967).

Assim, vê-se que a família protegida era a matrimonializada, resultante de casamento, e, saliente-se, esse apenas passou a poder ser dissolvido com a modificação feita pela EC $n^{\circ} 01 / 69$, que, posteriormente, foi regulamentada pela Lei $\mathrm{n}^{\circ}$ 6.515/1977.

Nessa mesma esteira, é interessante o posicionamento de Silvio de Salvo Venosa (2017, p. 16):

Os Códigos elaborados a partir do século XIX dedicaram normas sobre a família. Naquela época, a sociedade era eminentemente rural e patriarcal, guardando traços profundos da família da Antiguidade. A mulher dedicava-se aos afazeres domésticos e a lei não lhe conferia os mesmos direitos do homem. O marido era considerado o chefe, o administrador e o representante da sociedade conjugal. Nosso Código Civil de 1916 foi fruto direto dessa época. Os filhos submetiam-se à autoridade paterna, como futuros continuadores da família, em uma situação muito próxima da família romana.

Foi de forma paulatina e com muitos clamores e lutas sociais que esse paradigma foi - e vem sendo - alterado.

Mudou-se a perspectiva do sistema em relação à sociedade, e vice-versa, passando-se a valorizar o ser e suas potencialidades.

Novos princípios surgem e passam a ser aplicáveis à família, existindo uma nova sistemática metodológica a ser aplicada ao Direito das Famílias e sobre a qual os membros da sociedade, órgãos legisladores e julgadores devem se orientar. Nesse sentido:

Ora, com a Lex Fundamentallis de 1988 determinando uma nova navegação aos juristas, observando que a bússola norteadora das viagens jurídicas tem de ser a dignidade da pessoa humana (art. $1^{\circ}$, III), a solidariedade social e a erradicação da pobreza (art. $\left.3^{\circ}\right)$ e a igualdade substancial (arts. $3^{\circ}$ e $5^{\circ}$ ), o Direito das Famílias ganhou novos ares, possibilitando viagens em mares menos revoltos, agora em "céu de brigadeiro". A família do novo milênio, ancorada 
na segurança constitucional, é igualitária, democrática e plural (não mais necessariamente casamentária), protegido todo e qualquer modelo de vivência afetiva e compreendida como estrutura socioafetiva, forjada em laços de solidariedade. (FARIAS; ROSENVALD, 2014, p. 41-42, grifos dos autores).

A Constituição Federal de 1988, nomeada como Constituição Cidadã por valorizar os direitos e garantias fundamentais do ser humano, trouxe a dignidade da pessoa humana logo em seu primeiro artigo, como fundamento da República Federativa do Brasil.

Traz também em seu art. $3^{\circ}$, inciso IV, importante texto de lei que influenciará todo o sistema normativo: “Art. $3^{\circ}$ Constituem objetivos fundamentais da República Federativa do Brasil: [...] IV promover o bem de todos, sem preconceitos de origem, raça, sexo, cor, idade e quaisquer outras formas de discriminação.” (BRASIL, 1988).

Vê-se, nesse dispositivo da Constituição atual, que o que se pretende é a promoção do bem de todos e, pode-se pensar como desdobramento dessa norma, a proteção do desenvolvimento da personalidade no âmbito da família. Assim, não é a família, em si, que é protegida, e sim seus membros.

É simples, assim, afirmar a evolução de uma família-instituição, com proteção justificada por si mesmo, importando não raro violação dos interesses das pessoas nela compreendidas, para o conceito de uma família-instrumento do desenvolvimento da pessoa humana, evitando qualquer interferência que viole os interesses dos seus membros, tutelada na medida em que promova a dignidade das pessoas de seus membros, com igualdade substancial e solidariedade entre eles (arts. $1^{\circ}$ e $3^{\circ}$ da CF/88). (FARIAS; ROSENVALD, 2014, p. 42, grifos dos autores).

Outro importante ganho social foi a igualdade, que pode ser encontrada de forma expressa em diversos artigos da Constituição. Cita-se, a título de exemplo, o art. $5^{\circ}$, que consigna que todos são iguais perante a lei, não havendo que se fazer qualquer tipo de distinção entre as pessoas, e que entabula que homens e mulheres possuem os mesmos direitos e obrigações na ordem normativa brasileira.

Com isso, a família patriarcal, comandada pelo marido, que possuía mando e desmando sobre a esposa e os filhos, não mais se justifica nem tem amparo legal.

Como já mencionado, não é protegida a família, como uma instituição, e sim seus membros, ou a família-instrumento, que deve ser um ambiente para o desenvolvimento de personalidades individuais, realizações e, até mesmo, felicidade. Dessa feita, “[...] a proteção a ser conferida aos novos modelos familiares tem como destinatários (imediatos e mediatos) os próprios cidadãos, pessoas humanas, merecedoras de tutela especial, assecuratória de sua dignidade e igualdade” (FARIAS, ROSENVALD, 2014, p. 42, grifo dos autores). 
Assim sendo, a proteção ao núcleo familiar tem como ponto de partida e de chegada a tutela da própria pessoa humana, sendo descabida (e inconstitucional!) toda e qualquer forma de violação da dignidade do homem, sob o pretexto de garantir proteção à família. Superam-se, em caráter definitivo, os lastimáveis argumentos históricos de que a tutela da lei se justificava pelo interesse da família, como se houvesse uma proteção para o núcleo familiar em si mesmo. O espaço da família, na ordem jurídica, se justifica como um núcleo privilegiado para o desenvolvimento da pessoa humana. (FARIAS; ROSENVALD, 2014, p. 42, grifo dos autores).

Há, além do mais, a proteção constitucional da assistência social, que tem como um de seus objetivos a proteção à família (art. 203, I, CF/88).

Tem-se também o art. 226, que estabelece que a família é a base da sociedade. Nota-se, então, a importância desse instituto.

Art. 226. A família, base da sociedade, tem especial proteção do Estado.

$\S 1^{\circ} \mathrm{O}$ casamento é civil e gratuita a celebração.

$\S 2^{\circ} \mathrm{O}$ casamento religioso tem efeito civil, nos termos da lei.

$\S 3^{\circ}$ Para efeito da proteção do Estado, é reconhecida a união estável entre o homem e a mulher como entidade familiar, devendo a lei facilitar sua conversão em casamento.

$\S 4^{\circ}$ Entende-se, também, como entidade familiar a comunidade formada por qualquer dos pais e seus descendentes.

$\S 5^{\circ}$ Os direitos e deveres referentes à sociedade conjugal são exercidos igualmente pelo homem e pela mulher.

$\S 6^{\circ} \mathrm{O}$ casamento civil pode ser dissolvido pelo divórcio. (Redação dada Pela Emenda Constitucional $n^{\circ}$ 66, de 2010)

$\S 7^{\circ}$ Fundado nos princípios da dignidade da pessoa humana e da paternidade responsável, o planejamento familiar é livre decisão do casal, competindo ao Estado propiciar recursos educacionais e científicos para o exercício desse direito, vedada qualquer forma coercitiva por parte de instituições oficiais ou privadas.

$\S 8^{\circ} \mathrm{O}$ Estado assegurará a assistência à família na pessoa de cada um dos que a integram, criando mecanismos para coibir a violência no âmbito de suas relações. (BRASIL, 1988).

Pelas normas e princípios constitucionais mencionados, ainda que o art. 226, CF/88 mencione apenas três tipos de família (matrimonial, união estável e monoparental), não há que se falar em uma taxatividade de modelos familiares. Como a ligação entre os membros de uma família é declaradamente o afeto e o eudemonismo não há que se estabelecer de forma taxativa quais famílias terão reconhecimento e proteção do Estado.

Outrossim, deixando [a família] de ser compreendida como núcleo econômico e reprodutivo (entidade de produção), avançando para uma compreensão socioafetiva (como expressão de uma unidade de afeto e entreajuda), surgem, naturalmente, novas representações sociais, novos arranjos familiares. Abandona-se o casamento como ponto referencial necessário para buscar a proteção e o desenvolvimento da personalidade do homem. É a busca da dignidade humana, sobrepujando valores meramente patrimoniais. (FARIAS; ROSENVALD, 2014, p. 92, grifos dos autores).

Sabe-se que as expressões de afeto podem se dar de várias formas e, por isso, deve-se perceber que limitar legalmente essas expressões constituiria situação inconstitucional e, até mesmo, impossível, visto que escapam do alcance do Estado as relações de afeto existentes nas sociedades. 
Nesse mesmo sentido é a norma do art. 1.513 do Código Civil: “É defeso a qualquer pessoa, de direito público ou privado, interferir na comunhão de vida instituída pela família.” (BRASIL, 2002).

Ora, mesmo sendo o Código Civil norma infraconstitucional, foi recepcionado pela Constituição de 1988 e deve ser interpretado sob os preceitos desta. Assim, inspirada pelos princípios orientadores da República Federativa do Brasil e demais inscritos na Constituição Cidadã, não há que se falar em qualquer tipo de intervenção estatal no sentido de tentar reduzir o rol dos enlaces afetivos a serem considerados família. Manifestamente, essa vedação se estende também ao âmbito privado.

Gustavo Tepedino (2009b, p. 258) menciona que “As entidades familiares encontram-se constitucionalmente tuteladas, portanto, não em razão de algum pretenso valor intrínseco que lhes seja reconhecido, mas como instrumento para a realização da personalidade humana na solidariedade constitucional.”. E continua, aduzindo:

\begin{abstract}
Vale dizer, o constituinte protege o casamento (somente) na medida em que o núcleo conjugal serve de lócus ideal para a tutela da pessoa. No momento em que deixa de sê-lo, é o próprio constituinte quem prevê o divórcio (Art. 227, $\S 6^{\circ}$, CF), a garantir, assim, a liberdade de escolhas individuais e a confirmar o caráter instrumental das entidades familiares. Na mesma esteira, o art. 1.511 do Código Civil de 2002 determina que "o casamento estabelece uma comunhão plena de vida", de tal modo que a preservação do vínculo conjugal somente se justifica na medida em que a entidade familiar por ele constituída se mostre apta à realização [do] projeto de vida em comum digno da tutela segundo a ordem constitucional. (TEPEDINO, 2009b, p. 258-259).
\end{abstract}

Evidencia-se, assim, o princípio constitucional da pluralidade das entidades familiares, que visa a garantir os direitos relativos aos mais diversos arranjos familiares, isto é, que garante às famílias contemporâneas a especial proteção do Estado.

\title{
3 NOVOS MODELOS DE FAMÍLIA
}

Cláudia Viegas (2017), em sua obra "Famílias poliafetivas”, irá lembrar que a família moderna foi consolidada sob os auspícios da Idade Moderna, sendo diretamente afetada pela transição do modelo econômico feudal para a economia capitalista.

Sob essa perspectiva, Engels (2002) mostrou a relação intrínseca da formação familiar moderna com a necessidade da sociedade em promover a propriedade privada. Assim, a família, durante muito tempo, prestou-se a consagrar a sociedade capitalista que se formava. Era de fato a primazia do ter sobre o ser. 
Assim, o Direito das Famílias, que visa realizar-se em um contexto e sistema jurídico democrático, deverá estar atento à sua origem patrimonial para que possa superá-la em uma constante transformação.

Ressalte-se que:

O centro da tutela constitucional se desloca, em consequência, da exclusividade do casamento para a pluralidade das entidades que, fundadas ou não no vínculo conjugal, livre e responsavelmente constituídas, contenham os pressupostos para a tutela da dignidade da pessoa humana. (TEPEDINO, 2009b, p. 256).

Reforça-se a ideia de que não se protege o instituto da família, e sim a família como instrumento para o desenvolvimento da personalidade de seus membros, buscando assegurar a dignidade de cada um deles.

Para tanto, atualmente, já é possível reconhecer o desenvolvimento desse terceiro pilar do Direito Civil quando nos deparamos com as mais variadas espécies de famílias que esse direito visa trabalhar, lembrando que nem todas ainda são pacificamente reconhecidas.

São algumas das espécies de famílias: i) família heteronormativa ou patriarcal; ii) família monoparental; ii) família anaparental; iii) família mosaico ou plurilateral; iv) família homoafetiva; v) família simultânea ou paralela; vi) família poliafetiva.

Cada espécie de família receberá proteção e reconhecimento distinto, incluindo as novas espécies de famílias reconhecidas pelo “novo” Direito das Famílias, sendo importante lembrar que a família heteronormativa (um homem e uma mulher unidos pelo casamento ou união estável) trata-se de um modelo da família moderna já protegido pelo Direito Civil moderno que conta, ademais, com proteção constitucional expressa.

A família monoparental, talvez a mais aceita depois da família heteronormativa, é reconhecida atualmente após as conquistas dos movimentos feministas de todas as épocas, que emanciparam a mulher e que hoje permitem que ela permaneça sozinha (solteira, divorciada ou viúva) na condução da família, isto é, na formação da sua prole. Obviamente que não se exclui aqui a família monoparental formada pelo pai e sua prole, porém, cabe lembrar que esta formação familiar também só será aceita após a desconstrução promovida pelos movimentos feministas, que asseguram ao homem a possibilidade de ser “dono de casa”, isto é, de atuar nas funções que a divisão sexual do trabalho imputava exclusivamente às mulheres.

Também muito bem aceita pela sociedade, ressalvadas as devidas proporções, está a família anaparental. Ana vem do grego e significa “falta”. Assim, a família anaparental é aquela em que não haverá a figura de pai ou de mãe. Trata-se de um modelo familiar muito recorrente em casos em que 
a família é formada pelos avós e netos, irmãos maiores com irmãos menores, e outros laços familiares como tios e sobrinhos. “A convivência entre parentes ou entre pessoas, ainda que não parentes, dentro de uma estruturação com identidade de propósito, impõe reconhecimento da existência de entidade familiar batizada com o nome de família parental ou anaparental” (DIAS, 2015, p. 140).

Essa espécie de família é vista pela sociedade muitas vezes pelo aspecto da solidariedade e moralmente aceita por se enquadrar nos valores judaico-cristãos de altruísmo e benevolência. Ocorre que a ela também faltará proteção jurídica, por vezes, quando o poder familiar dos pais ainda não está desconstituído, interferindo muitas vezes nas questões de guarda, alimentos e até mesmo sucessões e eventuais discussões de pensão por morte.

Na sequência, podemos citar a família mosaico ou plurilateral, que será vista como família formada por mais de um núcleo familiar (duas pessoas se casam, porém já divorciadas, levam filhos que serão criados como irmãos, vivendo ainda a experiência do outro genitor com outra família) ou, ainda, quando há a formação da família reconstruída formada pela união de dois, sendo um deles genitor de uma criança que constituirá essa nova família como filho de ambos, ocorrendo muitas vezes até mesmo um processo de reconhecimento de paternidade/maternidade (fraudado ou não) pelo companheiro que não é genitor da criança.

A multiparentalidade, nessa estrutura familiar, ganha contornos de significativa importância. Nesse sentido, “A família mosaico tem assumido papel importante na sociedade, sobretudo em face da possibilidade de reconhecimento legal de mais de um pai e/ou mãe, delineando, assim, a tridimensionalidade das paternidades jurídica, biológica e socioafetiva.” (VIEGAS, 2017, p. 208).

A família homoafetiva é, talvez, a espécie que consagrou a mais expressiva evolução/transformação do Direito das Famílias brasileiro, ao ser reconhecida juridicamente e ter autorizada sua formalização pelo casamento ou união afetiva. No entanto, a luta pelo seu reconhecimento não foi fácil.

O caminho percorrido para o reconhecimento jurídico da família homoafetiva iniciou-se pelo reconhecimento da entidade familiar por meio do instituto da união estável, com discussões em sede de Ação Direta de Inconstitucionalidade (ADI 4277) e de Ação de Descumprimento de Preceito Fundamental (ADPF 132), ambas decididas em cinco de maio de 2011.

As ações constitucionais mencionadas permitiram que o Supremo Tribunal Federal (STF) modificasse o entendimento do disposto nos artigos 226, $\S 3^{\circ}$, e art. 1.723, do CC/02, equiparando a união estável homoafetiva à união heteroafetiva. O STF, em sua decisão, pautou-se nos valores do afeto, da dignidade, da igualdade e da solidariedade como fundamentos para tal reconhecimento.

Nesse sentido, Bernardo Gonçalves Fernandes resume a decisão da Suprema Corte: 
Nesses termos, o STF deu interpretação conforme a Constituição para o art. 1723 do Código Civil para excluir do dispositivo em causa qualquer significado que impeça o reconhecimento da união contínua, pública e duradoura entre pessoas do mesmo sexo como família. Reconhecimento que deve ser feito segundo as mesmas regras e com as mesmas consequências da união estável heteroafetiva (FERNANDES, 2017, p. 1.659-1.660).

No entanto, faltava ainda a garantia do casamento, para efetivação de direitos não resguardados pela união estável na prática. Assim, em 14 de maio de 2013, o Conselho Nacional de Justiça (CNJ), a fim de dar coerência à decisão do Supremo Tribunal Federal, determinou, por meio da Resolução 175, que os cartórios passassem a aceitar os registros civil de casamento fruto de união homoafetiva.

Em outro plano, de forma pouco pacífica, estão sendo discutidos, pelo direito brasileiro, a formação e o reconhecimento da família simultânea ou família paralela. Ao contrário da união homoafetiva, a família paralela é discutida em sede de controle difuso, concreto, o que talvez faça com que a discussão se prolongue ainda por anos.

A família simultânea ou paralela é aquela que por décadas foi reconhecida como concubinato. Segundo a consagrada jurista Maria Berenice Dias (2015, p. 280), “[o] concubinato, chamado de adulterino, impuro, impróprio, espúrio, de má-fé e até de concubinagem, é alvo do repúdio social, legal e judicial. Mas nem mesmo assim essas uniões deixam de existir”.

Como nos lembra Cláudia Viegas (2017), Nancy Andrighi, ministra relatora do Recurso Especial (REsp) no 1.348.458/MG de 2012, cita três correntes existentes, atualmente, que visam discutir o status jurídico da família simultânea.

A primeira corrente é a defendida por juristas mais conservadores, como Maria Helena Diniz, que defendem a monogamia como princípio e a fidelidade como valor, limitando o reconhecimento de qualquer tipo de família que seja construída em afronta a esses princípios e valores.

A segunda corrente é defendida por juristas como Álvaro Vilaça Azevedo, Rodrigo da Cunha Pereira e Zeno Veloso, e se apresenta como uma corrente moderna. Para esses autores, deve-se partir do princípio da boa-fé aliado à analogia ao casamento putativo, isto é, se um dos parceiros estiver convicto de que integra a entidade familiar sem conhecimento de que o outro é casado, então a esse devem ser resguardados os seus direitos perante as garantias familiares.

Já a terceira corrente tem como expoente Maria Berenice Dias. A autora defende que independe de boa-fé para que haja o reconhecimento da entidade familiar, deixando de considerar “dever de fidelidade” como um requisito da união. Nesse sentido, alerta a autora que "[p]erquirir a boa ou má-fé é tarefa complexa, além de haver o perigo de se cair no puro subjetivismo. A linha, a 
fronteira a partir de onde a boa-fé passa a ser má é por demais tênue, podendo ser praticamente invisível, inalcançável, imperceptível” (DIAS, 2015, p. 282).

De fato, entende-se aqui que a autora Maria Berenice Dias está correta, visto que a questão da boa-fé é um problema muito aquém da realidade das mulheres que, por estarem diante de uma sociedade extremamente machista e patriarcal, muitas vezes se encontram diante de situações que as mantêm ligadas a relacionamentos abusivos, mesmo quando há conhecimento de que seu parceiro não é solteiro ou divorciado.

Talvez essa não seja uma realidade próxima de pessoas bem afortunadas ou com o mínimo de acesso às informações. Porém, o Brasil é plural e constituído de realidades que, de tão distintas, parecem surreais. É preciso que o direito brasileiro, no entanto, atenda a todas as realidades: das mais possíveis às mais improváveis.

Nancy Andrighi, porém, em seu voto, reconheceu a corrente mais conservadora, citando a Lei 9.278/98 e os artigos 1.723 e 1.724 do Código Civil para fundamentar sua decisão. Assim, para a relatora, a dualidade, o objetivo de constituição de família, a ausência de impedimentos para o casamento e o dever de lealdade são requisitos fundamentais para o reconhecimento da entidade familiar. Ainda, a ministra entendeu que o “dever de fidelidade” seria pressuposto do dever de lealdade.

Ocorre que permanecer preso a essa ideia retrógada e patriarcal da fidelidade como um dever é impedir que a ideia de famílias plurais avance rumo à promoção da dignidade de seus membros, enquanto seres livres para o alcance da felicidade, como objetivo primeiro:

\footnotetext{
a família cumpre modernamente um papel funcionalizado, devendo, efetivamente, servir como ambiente propício para a promoção da dignidade e a realização da personalidade de seus membros, integrando sentimentos, esperanças e valores, servindo como alicerce fundamental para o alcance da felicidade. Do contrário, ainda viveremos como nossos pais (lembrando da canção), esquecendo que o principal sentido da evolução é não permitir que se mantenham os erros e equívocos de um tempo passado. (FARIAS, ROSENVALD, 2014, p. 43, grifos dos autores).
}

Isto é, torna-se desnecessária a institucionalização prévia da entidade familiar para que haja proteção, sendo esta um pressuposto inerente apenas à condição de ser dos sujeitos que compõe o núcleo familiar, conforme os princípios constitucionais que orientam o Direito das Famílias. Decisões como a de Nancy Andrighi mostram que a sociedade brasileira ainda se vale do fetiche da monogamia para reger suas relações.

Cláudia Viegas (2017), defensora do poliamor, nos lembra que o século XX foi marcado pelo amor romântico. Porém, com a revolução sexual (1960/1970) e com o desenvolvimento dos métodos contraceptivos, o sexo passou a ser visto como um ato de prazer, e não mais de procriação. 
Assim, a superproteção das entidades familiares monogâmicas perde o sentido por não mais proteger o ter, mas também por não desprivilegiar o ser.

Em outras palavras, a crença na monogamia deve ser algo tratado de forma individual, deve ser uma crença pessoal, que não deverá ser suportada pelo direito a tal ponto de desproteger as pessoas nas suas realidades. Dessa forma, passa-se a apresentar a espécie mais controvertida de família na atualidade: a família poliafetiva.

A poliafetividade é uma realidade que o Direito precisa encarar, como afirma Cláudia Viegas (2017). Trata-se de um elemento formador de um vínculo familiar não monogâmico, que representa a formação de um espaço plural, afetivo e democrático, cuja jurisdicionalização importa na promoção da dignidade da pessoa humana de seus membros.

Conforme a civilista Cláudia Viegas (2017, p. 236), “O poliamor nasce, então, da conclusão corajosa de que é possível amar mais de uma pessoa ao mesmo tempo, afinal, ninguém é de ninguém”. Assim, a família poliafetiva trata-se de uma união civil múltipla, com ânimo de constituir família (afetividade), com estabilidade, continuidade e publicidade. Deve haver, também, o consentimento de todos envolvidos.

Dessa forma, percebe-se mais uma vez - e, nesse caso, de forma até mais latente - a importância do reconhecimento do afeto para a caracterização da família, e não de conceitos fechados para tentar engessar essa instituição.

Desse modo, a família poliafetiva atende aos requisitos do Código Civil de 2002 (art. 1.723), cabendo observar que a diversidade sexual foi afastada por ocasião do julgamento das Ação Direta de Inconstitucionalidade 4277 e Ação de Descumprimento de Preceito Fundamental 123, em 2011.

Nessa lógica civil-constitucional, cabe lembrar que o reconhecimento da união poliafetiva é ainda a consagração da tutela qualitativa, que Anderson Schreiber e Carlos Konder (2016) defendem. Isto é, trata-se da primazia do ser (visto o respeito à dignidade dos membros desta entidade familiar), com a "funcionalização do ter" que os autores propõem, uma vez que irá também proteger os direitos de propriedade dos membros da família poliafetiva (SHREIBER; KONDER, 2016). Assim, mostrase necessário o reconhecimento desta (e de todas as outras) espécie familiar, a partir da superação “[...] do dogma da subsunção e a concepção da interpretação como operação meramente formal [...] [;] é a importância de priorizar, na análise do instituto [família], seu perfil funcional, seus efeitos, passando do ‘como ele é’ para o ‘para que ele serve’” (SHREIBER; KONDER, 2016, p. 13).

Em outras palavras, é desnecessária a existência de espécie específica de família para que se reconheçam seus valores, direitos e garantias. Nessa perspectiva, Maria Berenice Dias (2015, p. 139) 
nos ensina que: “[n]egar a existência de famílias poliafetivas como entidade familiar é simplesmente impor a exclusão de todos os direitos no âmbito dos direitos das famílias e sucessório”.

Foi baseado no ideal de respeito à dignidade da pessoa humana que a tabeliã Fernanda Freitas Leão, do $15^{\circ}$ Ofício de Notas do Rio de Janeiro, na Barra da Tijuca, reconheceu, em 2015, a união poliafetiva de três mulheres e lavrou escritura jurídica, formalizando tal união. A escritura declara vínculo existente, conjugalidade múltipla e lhes garante segurança jurídica (ou ao menos deveria garantir).

Assim, as pessoas em uma união poliafetivas poderão ter garantidos os direitos de regime de bens, filiação, multiparentalidade, dissolução parcial ou total e de sucessões, isto é, serão, finalmente, protegidas pelo ordenamento jurídico, que se pretende consolidar como democrático.

Obviamente, as escrituras lavradas suscitaram alguns posicionamentos contrários e, em janeiro de 2016, o CNJ recebeu demanda da Associação de Direito de Família e Sucessões (ADFAS) pleiteando a proibição desses registros em cartórios (VIEGAS, 2017, p. 306). Em sede de liminar a proibição foi negada, porém Nancy Andrighi determinou a suspensão de novas lavraturas até que a decisão final seja proferida.

Ainda que todas essas ações contrárias ao reconhecimento de espécies de famílias, como a simultânea e a poliafetiva, logrem êxito, a discussão em si tem sido muito válida. Em sede de Recurso Extraordinário, por exemplo, o ministro Carlos Ayres Brito determinou o fim do uso da expressão “concubinato” em veículos oficiais de informação jurídica, a fim de afastar o uso de expressões pejorativas que enfraquecem a dignidade de quem busca pelos seus direitos (RE 590779/2009).

Cabe agora ao Direito Civil, e ao Direito das Famílias, continuar a avançar sob os auspícios da Constituição Federal, dos Tratados de Direitos Humanos e, consequentemente, de uma hermenêutica constitucional, para a contínua construção do que Jacques Derrida chamou de Democracia do porvir.

E o primeiro passo para isto, como propõem Luiz Edson Fachin e Carlos Eduardo Pianovski [201-], é prescindir de modelos pré-definidos para a proteção da família democrática. Assim, será possível a contínua (des)construção do Direito que hoje já não é mais da família normativa, mas sim, direito das famílias, evidenciando a sua mais latente pluralidade

Só assim será possível a felicidade existencial, concretizando de uma vez por todas o princípio da eudaimonia e reconhecendo a família como ambiente de livre desenvolvimento da personalidade e consequentemente, da dignidade da pessoa humana. 


\section{CONCLUSÃO}

O presente artigo teve como escopo a proteção conferida às famílias pela Constituição brasileira de 1988. Nomeada “Constituição Cidadã”, ela trouxe um rol amplificado de direitos atribuídos ao ser humano, visando maior proteção do indivíduo e estabelecimento de garantias fundamentais inafastáveis.

Neste ano de 2018, a Constituição Cidadã completa seu trigésimo aniversário. Contudo, ainda que seu intuito seja a proteção, há ainda hoje discussões sobre a proteção ou desproteção de alguns modelos contemporâneos de família.

Neste texto mencionou-se, inicialmente, sobre a constitucionalização do Direito Civil, marco importante para o direito privado em que as esferas de autonomia eram vastas. Com essa nova

metodologia, passou-se a interpretar as regras do Direito Civil à luz da Constituição e de seus preceitos.

Na sequência, discorreu-se sobre a proteção constitucional concedida às famílias e aos novos modelos existentes socialmente, a fim de demonstrar as mais variadas formas familiares contemporâneas já reconhecidas pela Carta Magna e, consequentemente, pela comunidade jurídica.

Sabe-se que a proteção da família é algo ainda complexo, sempre debatido, e a extensão da proteção constitucional é interpretada de acordo com as convicções de cada intérprete. Atualmente, existem projetos de lei que visam estabelecer de forma taxativa quais núcleos são considerados família, assim como existem projetos que visam alargar esse rol.

Ora, conforme mencionado, o que se protege constitucionalmente não é a família-instituição, aquela que se justifica por ela mesma e em que não há a valoração dos seus membros. O que os preceitos constitucionais deixam bem claro é que a proteção é dada à família-instrumento, para que cada membro possa desenvolver livremente a sua personalidade dentro desse núcleo social, ligado aos outros membros pelo afeto e buscando a felicidade.

O afeto é entendido como o elo da família, sendo inconstitucional e impossível tentar limitar essa expressão de carinho, devendo estar submetido apenas às normas morais de cada indivíduo.

Por todo o exposto, entende-se que a proteção constitucional abarca todas as formas de família possíveis, imagináveis e inimagináveis, desde que não haja violação de direitos e que nessas famílias haja ambiente propício ao livre desenvolvimento de seus membros. Assim, tendo em vista o princípio constitucional da pluralidade das entidades familiares, qualquer norma que vise a limitar ou diminuir esta garantia deverá ser considerada inconstitucional e, consequentemente, extirpada do sistema jurídico brasileiro. 


\section{REFERÊNCIAS}

BRASIL. Constituição (1967). Constituição da República Federativa do Brasil de 1967 (Redação dada pela Emenda Constitucional $n^{0}$ 1, de 17.10.1969). Diário Oficial da União, Brasília, 20 out. 1969. Disponível em: <https://goo.gl/zNmzDv>. Acesso em: 25 abr. 2018.

BRASIL. Constituição (1988). Constituição da República Federativa do Brasil. Diário Oficial da União, Brasília, 5 out. 1988. Disponível em: <https://goo.gl/HwJ1Q>. Acesso em: 25 abr. 2018.

BRASIL. Lei $\mathrm{n}^{\circ} 10.406$ de 10 de janeiro de 2002. Institui o Código Civil. Diário Oficial da União, Brasília, 11 jan. 2002. Disponível em: <https://goo.gl/tB90g>. Acesso em: 25 abr. 2017.

DIAS, Maria Berenice. Manual de Direito das Família. 10. ed. rev. atual. e ampl. São Paulo: Revista dos Tribunais, 2015.

ENGELS, Friedrich. A origem da família, propriedade privada e do Estado: trabalho relacionado com as investigações de L. H. Morgan. 16. ed. Rio de Janeiro: Bertrand Brasil, 2002.

FACHIN, Luiz Edson; PIANOVSKI, Carlos Eduardo. A Dignidade da Pessoa Humana no Direito Contemporâneo: uma contribuição à crítica da raiz dogmática do neopositivismo constitucionalista. Revista eletrônica do Curso de Direito OPET, Curitiba, Revista $n^{0}$ 5, [201-]. Disponível em: $<$ https://goo.gl/yskJUv>. Acesso em: 25 abr. 2018.

FARIAS, Cristiano Chaves de; ROSENVALD, Nelson. Curso de direito civil: direito das famílias. v. 6. 6. ed. rev., ampl. e atual. Salvador: Juspodivm, 2014.

FERNANDES, Bernardo Gonçalves. Curso de Direito Constitucional. 9. ed. rev., ampl. e atual. Salvador: Juspodivm, 2017.

MORAES, Maria Celina Bodin de. Perspectivas a partir do direito civil-constitucional. In: LEAL, Pastora do Socorro Teixeira (Coord.). Direito civil constitucional: e outros estudos em homenagem ao prof. Zeno Veloso: uma visão luso-brasileira. São Paulo: Método, 2014. Estudos de Direito Constitucional e afins, Capítulo 5 [e-book].

SHREIBER, Anderson; KONDER, Carlos, Uma Agenda para o Direito Civil Constitucional. Revista Brasileira de Direito Civil, Rio de Janeiro, v. 10, n. 4, p. 9-27, out-dez 2016.

SZANIAWSKI, Elimar. Direitos de personalidade e sua tutela. 2. ed. rev., atual., e ampl. São Paulo: Revista dos Tribunais, 2005.

TARTUCE, FLÁVIO. O novo CPC e o Direito Civil. 2. ed. rev., atual. e ampl. Rio de Janeiro: Forense, 2016.

TEPEDINO, Gustavo. A legitimidade constitucional das famílias formadas por uniões de pessoas do mesmo sexo. In: TEPEDINO, Gustavo. Temas de direito civil. Tomo III. Rio de Janeiro: Renovar, 2009b. Pareceres, Capítulo 1, p. 253-277. 
TEPEDINO, Gustavo. Normas constitucionais e de Direito Civil na Construção Unitária do Ordenamento. In: TEPEDINO, Gustavo. Temas de direito civil. Tomo III. Rio de Janeiro: Renovar, 2009a. Ensaios, Capítulo 1, p. 3-19.

VENOSA, Sílvio de Salvo. Direito civil: Família. v. 5. 17. ed. São Paulo: Atlas, 2017 [e-book].

VIEGAS, Cláudia Mara de Almeida Rabelo. Famílias poliafetivas: uma análise sob a ótica principiológica jurídica contemporânea. Belo Horizonte: D’Plácido, 2017.

VILELA, João Baptista. Variações impopulares sobre a Dignidade da Pessoa Humana. In: Superior Tribunal de Justiça. Doutrina. Edição comemorativa 20 anos. Abril, 2009. Disponível em: <https://goo.gl/uG2EKU>. Acesso em: 29 abr. 2018.

Maria Walkíria de Faro Coelho Guedes Cabral Doutora e Mestre em Direito Público pela PUC Minas. Professora substituta na Universidade Federal de Lavras. Coordenadora do núcleo jurídico da Casa de Referência da Mulher Tina Martins.E-mail: mwcabral@gmail.com

Jéssica Rodrigues Godinho

Mestranda em Direito Privado pela PUC Minas (Bolsista FAPEMIG). Especialista em Direito Civil Aplicado pela PUC Minas. Graduada em Direito pela PUC Minas. Advogada. E-mail: jessica.godinho@yahoo.com.br 